\title{
Children with Cerebral Palsy in Primary Health Care
}

\section{Rawa Al Ameri*}

Family Medicine Specialist, Al-Mustansiriyah University, Iraq

*Corresponding author: Rawa Al-Ameri, Family Medicine Specialist, Al-

Mustansiriyah University, Iraq, Email: dr_rj1983@yahoo.com

\section{Editorial}

Volume 2 Issue 5

Received Date: September 03, 2019

Published Date: September 13, 2019

DOI: $10.23880 /$ jqhe- 16000135

\section{Editorial}

Cerebral palsy is a group of disorders that cause developmental disabilities that result in considerable functional limitations. It affects a child's ability to move and maintain balance and posture [1]. Cerebral palsy is the most common physical disability in childhood that occurs in 1 in 500 live births. 2'3 CP cases are so frequent in daily routine work in primary health care with emotional and devastating effect on family and their health provider as the child may suffer from spasticity, uncontrolled movements, intellectual disability, seizures, and problems with vision, hearing, or speech.

Early diagnosis will provide better outcome by optimizing neuroplasticity and function [2]. This requires more attention in routine child visit and creation of new programs in primary health care for early detection and follows up. The Middle East, including Iraq, needs more consideration for CP cases as the clinicians need to listen to the mothers about their experiences and obstacles in raising a child with $\mathrm{CP}$, providing them suitable solutions. Family-centered care needs to be a cornerstone of rehabilitation services and enabling the health care practitioners to use the family-centered model when working with cerebral palsy children $[3,4]$.

Although hypoxia or ischemia at birth is forming a small percent of CP causes according to recent studies, it is still somewhat a preventable cause [5]. The role of primary health care in this point is represented by antenatal care follow up, health education of mothers about safe labor and the strict supervision of midwives.
Unfortunately, untrained and non-certified midwives are so common in Iraq. It is so frequent to see a pregnant with obstructed labor or pelvic disproportion forced to have normal labor by a midwife with devastating consequences to mother and baby. Strict rules should be legislated with continuous training of certified midwives, in addition to health lectures to women and midwives.

\section{References}

1. Maenner MJ, Blumberg SJ, Kogan MD, Christensen D, Yeargin Allsopp M, et al. (2016) Prevalence of cerebral palsy and intellectual disability among children identified in two U.S. National Surveys, 20112013. Ann Epidemiol 26(3): 222-226.

2. Novak I, Morgan C, Adde L, Blackman J, Boyd RN, et al. (2017) Early, accurate diagnosis and early intervention in cerebral palsy: Advances in diagnosis and treatment. JAMA Pediatr 171(9): 897-907.

3. (2018) What is Cerebral Palsy? Centers for Disease Control and Prevention.

4. Mohamed Madi S, Mandy A, Aranda K (2019) The Perception of Disability Among Mothers Living With a Child With Cerebral Palsy in Saudi Arabia. Glob Qual Nurs Res 6: 1-11.

5. MacLennan AH, Thompson SC, Gecz J (2015) Cerebral palsy: Causes, pathways, and the role of genetic variants. Am J Obstet Gynecol 213(6): 779-788. 